Article

\title{
Chinese Migrant Perceptions of Africans: Understanding Confucian Reflexive Politics in Southern Africa
}

\author{
Micah Petersen ${ }^{1,2}$ and Saleem Ali ${ }^{3,4, *(\mathbb{D})}$ \\ 1 Department of Geography, University of Delaware, Newark, DE 19716, USA; mdpete@udel.edu \\ 2 Schwarzman Scholar, Schwarzman College, Tsinghua University, Beijing 100084, China \\ 3 Department of Geography \& Energy and Environmental Policy Program, University of Delaware, Newark, \\ DE 19716, USA \\ 4 Sustainable Minerals Institute, University of Queensland, St. Lucia, QLD 4070, Australia \\ * Correspondence: saleem@udel.edu; Tel.: +1-30-2831-0871
}

Received: 7 August 2018; Accepted: 18 September 2018; Published: 25 September 2018

\begin{abstract}
In this paper, we use a qualitative reflexive approach to understand the dynamics of Chinese migrant perceptions of Africans upon arrival in Africa and the changes in their views upon returning to China. The research is based on in-depth, semi-structured field interviews with Chinese workers and managers in Mozambique and South Africa, as well as interviews with returning migrants to China, carried out in Beijing. Thus, we are able to gauge the learning experience that occurs and how the underlying Confucian philosophy that has been embraced by the Chinese polity manifests such changes in perception. The research suggests that there is a positive learning process which occurs through the migrants' experience and underlying racial stereotypes of Chinese regarding Africans are eroded. Confucian framing of China's role in Africa is also mitigated towards a more hybridized view of African cultures and societies that reflects to adaptive propensities of contemporary Chinese society.
\end{abstract}

Keywords: China; migration; Africa; Confucian; race; perception; migrant

\section{Introduction}

The topic of migration in China is often brought up under the context of internal migration from rural to urban areas, or internationally from "civilized" to "barbaric" lands (Chen 2012). Despite the derogatory and neocolonial cadence of the latter, the migratory relationship between China and many African nations remains largely amicable and, unlike European colonialism of the continent of yesteryears, Africans, of course, retain veto power over investment. In this paper, we seek to consider the learning process which occurs through Chinese migration to Africa by considering the engagement as a reflexive process (Archer 2007). Our aim is to see if the process of engagement and in-depth field exposure of Chinese in Africa leads to a change in their perception of Africans and how this may ultimately impact China-Africa relations. We are conscious of the diversity of countries and cultures that exist within the African continent but for the purposes of this analysis the term "African" is an appropriate unit of analysis, given the collective perception of Africans as a baseline of the migrant's experience. Furthermore, in context of this research, "African" only refers to black residents of the continent.

Many examples, from the massive Bank of China sign a person sees when entering Robert Mugabe International Airport in Zimbabwe, to a sign written in Mandarin Chinese placed above the Chinese built national stadium in Maputo, Mozambique which states, "The friendship between China and Mozambique will prevail like heaven and earth" portray the magnitude of the relationship between China and Africa. They also hint toward the migration associated with it (Cardenal and Araújo 2013). 
Understanding the motives behind emigrating from China to Africa is integral in comprehending Chinese immigrant's perceptions of Africans, and better understanding how Chinese natives relate to African locals and vice versa.

According to Park, three types of immigrants make up Chinese relocating to Africa: Employees of Chinese-State owned Companies; independent, small-time, entrepreneur-oriented migrants seeking economic opportunities; and transit migrants (Park 2009). Different authors provide varying definitions as to what type of migrants come from China. For example, Ma Mung claims three types of Chinese migrants arrive in Africa: Temporary migrants linked to public works and infrastructure projects, an entrepreneurial migration flow made up of merchants, and a group of laborers using Africa as a pit-stop in hopes of migrating to Europe (Kuang 2008b). Migrants also include commercial supervisors, temporary agricultural workers, construction workers, shop sellers, and entrepreneurs, argues Cardenal (Cardenal and Araújo 2013). While the type of migrant might be debated, what is much less debatable is that each of these migrants are adaptable and able to find their niche in society. South Africa's Chinese population resides in what is arguably the most race-conscious country in the world (Yap 1996). They are a population who, despite their minority status, have impacted the employment field and development overall (Yap 1996). While Yap authored her book in 1996, Park notes that since then, the number of migrants from China to Africa has jumped significantly (Park 2009). With this as the case, Yap's viewpoint becomes even more integral to understanding the Chinese perception of local black Africans.

\section{Historical and Ideological Context}

\subsection{Ethnicity and Race}

The relationship between African states and China is extremely complex. In many ways, despite China's attempts to differentiate itself from colonial powers by empathizing with African states as a fellow nation who experienced poverty, China is criticized for exploiting Africa. Many African leaders have turned to China for investment purposes and view them as a strong ally. Nevertheless, a tension often remains between Chinese and people of African origin. Underlying many of China's foreign developments is a strong desire for China to return to its place at the center of the world stage (Link 2015). Link believes that, "To be Chinese still means to be [believe that one is] a part of a civilization that has primacy in the world" (Link 2015). This has led to a deep-seated racism at the center of modern Chinese society and to a racial prejudice against other "races", such as blacks in Africa (Tuttle 2015).

This history of "race" and "ethnicity" in China extends back to the 4th century BCE during the Spring and Autumn Period. Since that time, zulei, a term which has become "emblematic of sinocentrism", has drawn delineations between Han Chinese, and the "other" (Chin 2012). In fact, the old saying goes, “非我族类, 其心必异” or rather, “If they are not of our zulei [race], they are sure to be of a different mind" (Chin 2012). While this concept seems to communicate the divisiveness between Chinese ethnicities and race, the concept of Chinese unity and identity is not clearly defined. This literature review seeks to provide a background on ways in which many Chinese peoples have perceived race historically, and draws a connection between that historical perspective and today's current outlook.

While the modern term of "race" in China is quite new, the roots of race, however, are found deep in China's antiquity. The understanding of ancient China's Confucian definition of "race", zulei in classical Chinese, seems to be contradictory. On one hand, it labeled those not of "Chinese ways" as barbarians, essentially defining them as the "other". On the other hand, it taught that the barbarian, or other "race", could be absorbed through a change in cultural self-identification. This process of self-identification, or "becoming Chinese" is known as Sinicization. Debate exists about the truth behind Sinicization meaning "becoming Chinese" since many would argue the Chinese had only recently been, Sinicized (Crossley 1990). Regardless of how long ago the Chinese became Sinicized, history indicates that starting in at least the third century BCE, Sinicization was utilized to create a unifying identity in China. 
The Chinese drew a difference between the waiyi (outside barbarians) and the neiyi (inside barbarians) (Dikötter 2015). It is the negative perception the Chinese held toward the waiyi which grew out of racial constructs; whereas, the perception of the neiyi resulted from ethnic constructs (Dikötter 2015). In other words, the subhuman regard for outside barbarians was built on judgments of phenotypical traits, or what is often called "race". The absorption of outside barbarians required transformation, or rather, they must become "un-barbarian." As we look at the classics, specifically, the historical usages of zulei, early evidence of racial prejudice becomes apparent. The prejudice is even apparent in the name for China. The name for China in Chinese is zhongguo, which literally translates to "center country". The focus on being at the center gives a glimpse into where many Chinese people believed China stood on the global stage, superior to all outside its borders. Non-Chinese people outside of the central-system were viewed as inferior and expected to pay tribute to, and learn from, zhongguo (Link 2015).

This form of racial discrimination where people are only accepted if they become more like the group who is expected to accept them appears bluntly in Chinese culture, as seen with zuozhuan (Chin 2012). The zuozhuan played a fundamental role in establishing the original theory of Han-race lineage, as written by the philologist, Zhang Taiyan (Chin 2012). The zuozhuan which Chin is referring to is the ancient saying mentioned above, "If he is not of our zulei (race), his mind is sure to be different (fei wo zulei, qi xin bi yi)" (Dikötter 2015).

The Manchu period serves as a prime example of how race was used to create a perception of outsiders. As the conquering force, the Manchu's understood the power of racial constructs, and in many ways, the continued formation of "Han" identity was a specific social construction which served a political purpose. From the 1600s to the 1900s, the Manchu's labored to create a social construct which, "generated a strong sense of nationalistic-racial consciousness among Chinese" (Elliott 2001). The Han connection goes far beyond cultural components, and was created with the influence of political and economic relations (Tapp 2012).

Over time, the idea of the "other" as a different race, and in some instances sub-human, has most likely inculcated racial prejudice within the subconscious of many Han peoples. The magnitude of differences between Han Chinese and other Chinese minority groups is interesting considering that many eastern traditions and races are often viewed as homogeneous in comparison to the West. In other words, the West often views Asia as a singular ethnic and racial group, and neglects the differences which Asian people groups often recognize amongst themselves. The US has been labeled the "melting pot", and on closer inspection, one could argue that the Han race is equally as much of a gathering of traditions, or "mixed blood" as the US (Teng 2012). While Han people may be of the same race as all other Chinese peoples according to western perspectives-based on the color of their skin - the Han people do not share common customs, culture, language, religion, or political ideology with the majority of other Chinese "races" (Teng 2012). Within the Han themselves, a great diversity exists. When talking about the Chinese race, it is not a "race" only in the terms of color of skin, but an identity which has been fabricated to be perceived as superior based off a conglomeration of physiological features.

One must also give thought to the early influential role geography and race played in creating the identity of the Han people. Geography, and specifically place, played a significant role in how Chinese intellectuals defined "Hannes" (Chen 2012). The Chinese's, specifically "pure Han's", ability to expand to new geographic places, and furthermore, adapt and migrate to these new places is read almost with the same attitude of the US's Manifest Destiny, and very well could explain some of the prejudices toward blacks (Chen 2012). Just as Americans viewed western migration as fulfilling their destiny to conquer unknown lands, the Han's history of migration throughout China and now the world could be viewed as the Han people fulfilling their destiny to rule over any land they encounter.

The common perception of Chinese elites toward blacks aligns with the ancient perception regarding raw and cooked: An ancient idea of pure verse evil from Chinese tradition. Whenever blacks were fed cooked meat and subsequently endured diarrhea, they were said to undergo "changing the 
bowels" to become half-human (Mullaney et al. 2012). The emphasis placed on skin color dates to 221 BCE in China where black, white, and yellow skin denoted social classes and aesthetic values. The racial prejudice in China was not merely relegated to blacks. Dikötter's book opens westerner's eyes to the perception China had of "the devils from the dark continent", and sets a firm foundation for understanding why the Chinese population often discriminated not just against blacks, but any different color, geographical origin, and even religion (Dikötter 2015). For the purpose of this study, it is important to keep in mind that the presence of racial inequality, and the fact that many victims of racial inequality fail to have their history and story told, creates a situation where prejudiced perceptions are fostered because of a lack in knowledge about "the other's" history.

\subsection{Summary of Political and Economic Chinese-African Relationship}

The relationship between China and Africa first reached its pinnacle in the 1950s and 1960s as African nations struggled for independence from colonial powers. During this time, future states such as Namibia, Mozambique, and Zimbabwe began to organize movements for independence from Germany, Portugal, and England, respectively. During the Cold War, there was also a slow rise of Chinese influence on what was then called "The Third World" as a means of ideological evangelism. China's competition with the West has been well-documented during this period as well (Brazinsky 2017).

As these movements gained recognition on a world stage, Russia and China were in the midst of expanding as communistic powers. Both states understood the necessity of attaining support in the United Nations (Jinyuan 1984). They also understood the importance of gaining support from soon to be independent African states (Jinyuan 1984). As two states which had experienced significant poverty, yet also envisioned a future of sharing global hegemony, Russia and China crafted arguments in which developing states, and liberation parties in Africa could find common ground.

The importance of political ties with African states, from the Russian and Chinese perspectives, is adequately exemplified by Zimbabwe's history. As the Ndebele tribe in western Rhodesia built up the ZAPU independence party, Russia promised to support their cause with weapons, uniforms, and ammunition (Coltart 2016). Simultaneously, China partnered with the Shona tribe in the east, and the ZANU party. In hopes the ZANU party would one day be the ruling party in an independent Zimbabwe, China supported Mugabe's party with weapons, uniforms, and ammunition as well (Coltart 2016). Russia and China crafted these strategic relationships in hopes of gaining the country's support following their independence and ultimately a partner vote in the United Nations General Assembly. Similar relationships were seen in Mozambique when the Renamo independence party and China worked to build a partnership of mutual support (Coltart 2016).

While the crumbling of the official political partnerships due to the implosion of the USSR broke many of the strong ties between Russia and China and African states, a perception of Africa and its peoples had been inculcated within the Chinese mindset. The Chinese Government's perception of Africans was one which portrayed the Africans as pawns to be used to help China achieve its political objectives. The time between 1950 and 1978 explains how China and Russia's primary mission for supporting African state's independence was to attain their political allegiance (Li 2005). Due to the historical negative perception of blacks, and the Chinese government's political exploitation of many Africans, many members of the Chinese population most likely viewed Africans with a prejudiced, partially-racist mindset.

The example of Zimbabwe varies greatly from China's involvement in west African states. While the relationship between China and east and southern African states dates back centuries, west African states did not establish consistent relationships with China until the 1980s (Tschakert 2016). With relations spanning only forty years, a distrust and tension between blacks and Chinese is much more evident. As Tschakert points out, Chinese artisanal miners in Ghana were rounded up and criminalized for their small gold mining efforts (Tschakert 2016). The Chinese migrants are viewed by locals and the government as a danger and are often not welcome. The difference between west 
African and east African states' relationship with Chinese and their perception of Chinese migrants places this study in context and ensures that the two regions are not perceived as the same.

The relationship in the 20th century between China and various African states was, in many ways, a core manipulation of peripheral states. While China did not yet stand as a global power at the time, it stood decades ahead of most African states in development indicators and played a developmental relatability, only to secure support in the United Nations. As China's relationship with African nations continues to develop in the 21st century, a clear pivot has been made away from ideological partnerships and toward economic ones (The Economist 2014). Cumulatively, the literature regarding how the concept of race was constructed in China, and its past relationship with African states tells the story of a complex relationship between two regions whose partnership is growing in global importance and should continue to be examined through a variety of lenses.

\subsection{South African Context}

South Africa is home to over half of all Chinese migrants in Africa. Durban, South Africa along with Johannesburg and Port Elizabeth, host the largest populations of Chinese migrants throughout the country (Statistics South Africa 2011). The first migrants from China bound for Durban arrived in 1904 as a "coolie", or rather "Asian labor" (Liggett 2007). This group of Asian Labor arrived at the bequest of Herbert Hoover when he was director of Chinese Engineering and Mining Corporation (Liggett 2007). Since their first arrival, the number of Chinese migrants has consistently grown.

As of 2009, nearly 350,000 Chinese migrants resided in South Africa, and by 2011 that number rose to nearly 500,000 (Statistics South Africa 2011). Over the past several decades, South Africa has witnessed a significant increase in Chinese migrants; and while the majority live in Johannesburg, this research was conducted in Durban due to safety reasons (Lin 2014). Upon arrival in South Africa, it was evident that many of the Chinese migrants in South Africa immigrated to work as small-time entrepreneurs (Lin 2014). All but one interview conducted in Durban was with an individual who was a shop owner or business owner. Due to the prevalence of small-time entrepreneurs in South Africa, most relationships between locals and migrants occur within the owner's shop. Furthermore, Durban is the home of China's Great Wall Motor distribution center (Cardenal and Araújo 2013). Durban is also home to a large amount of Chinese mineral refineries (Cardenal and Araújo 2013).

Compared to other African states, South Africa has the largest population of white settlers. While only 8.4 percent of the population, the settler's presence does impact the way local blacks interact with immigrants and non-blacks (Statistics South Africa 2011). This is important to note due to the role it plays in relationships between Chinese immigrants and blacks. For example, since blacks have lived with white migrants for generations in South Africa, they could either be more predisposed to fear immigrants from China, or more likely to hold a less skeptical perception of them because of their long history with other non-black immigrants.

\subsection{Mozambican Context}

China's relationship with Mozambique is unique in comparison with other African countries, as it is one clothed with caution and compromise (Roque 2009). Throughout Africa, Mozambique is one of four states with Portuguese language and culture (Angola, Mozambique, Cape Verde, Guinea Bissau represent the remaining other states) but has the most robust trading history with Asia. China's relationship with Mozambique reaches back to the time of Portugal's colonialism of Mozambique, when many Chinese migrants worked in the colony (Ilhéu 2010). Originally, Mozambique served as China's direct tie to Europe via Portugal (Ilhéu 2010). To this day, due to the continued use of Portuguese as a national language, Mozambique remains a corridor for China to reach Europe economically.

Mozambique's relationship with China, while it has expanded greatly over the past two decades, found more formal ties in the 1960s with China's support of the liberation front, Frelimo (Chichava et al. 2013). When Mozambique officially claimed independence, China was the first nation 
to recognize them as a sovereign state (Ilhéu 2010). While communist USSR supported other fronts in various African states, China supplied Frelimo with economic, political, and military support (Chichava et al. 2013). In 1975, China formed formal diplomatic ties with Mozambique following independence (Chichava et al. 2013). In 1977, despite support from China, Mozambique moved closer to the Soviet Union and declared itself a Marxist-Leninist state (Roque 2009).

Nevertheless, relations with China remained peaceful. During the 1990s, after moving away from its socialist policies, Mozambique became a model for co-operating with western states (Roque 2009). As China increased its relationship with Mozambique, the participatory governmental structure highlighted its uniqueness in comparison with other African states, such as Angola and clearly focused its impact in Mozambique on infrastructure and resources (Roque 2009). While the level of involvement is not quite to China's liking, many Mozambicans hold China's relationship in high regard due to the lack of benefits reaped from European national partnerships over the past several generations (Roque 2009).

Several Chinese firms have also built significant infrastructure, as well as electricity grids, in Mozambique (Kuang 2008a). The most significant project for China includes the national stadium constructed just outside of Maputo (Cardenal and Araújo 2013). Furthermore, China has indicated its interest in building even stronger relations with Mozambique by forgiving a twenty million-dollar US debt, announcing that Mozambique would be the first African country to receive one of Africa's 14 special agriculture technology demonstration centers, and building the new parliament building in Maputo (Ilhéu 2010).

According to Park, in terms of migration numbers, Mozambique remains a relatively midsized destination for Chinese migrants. As of 2006, Mozambique was home to nearly 2000 Chinese migrants, which is over double the amount present in 2001 (Park 2009). Considering the continuous exponential rise of Chinese migrant numbers in Africa, and the increase in amount of Chinese spending in Africa, it is safe to assume that nearly 4000 migrants currently reside in Mozambique.

\subsection{Confucianism}

The study of Confucianism is vast and a comprehensive understanding is beyond the limitations of this paper. Nevertheless, several aspects of Confucianism are integral to this study and Chinese immigrant's perceptions of black Africans. The Confucian values most pertinent to this study include education, development and social hierarchy. For over two millennia, Confucianism has played an integral role in the development of Chinese culture. As an individual, Confucius is held in the highest regard throughout Chinese society, but it is his work, more than him as an individual which remains influential. The Confucian school of thought is not merely limited to the works of Confucius, but rather an umbrella term applied to works unified around similar values. The Five Classics of Confucianism formed the core for the symbolic system of how China determines social groups (Dikötter 2015).

Today, the influence of Confucianism within Chinese society remains noticeable. Despite the lack of conscious practice of Confucianism, its ideals and views regarding morality still heavily influence modern day Chinese thought (Ni 2002). Confucianism is not utilized as a religion, but an inherent aspect of Chinese culture which has influenced the development of Chinese thought and morality for centuries. As Chen and Chung state, Confucian hierarchy, family system, and emphasis on education continues to impact communication within society at-large today (Chen and Chung 1994). More specifically, the Confucian mindset has molded the Chinese's modern perception of race and the new world order (Dikötter 2015). With the exception of several decades where the government banned Confucianism, it has remained a central tenant to the Chinese way of thinking. For this study, I engage solely with the Confucian school of thought and not Confucius as an individual.

The Confucian understanding of education differs from the western perspective. Education is holistic, and goes beyond the acquisition of knowledge in a subject. Confucian education's goal is to raise one's sushi (quality) through consistent, virtuous practice. The Chinese word for learning, xue, refers to inner-cultivation, which aligns with the Confucian focus on the responsibility of everyone to 
fulfill his or her role as a citizen of society (Ni 2002). In many ways, this version of education can be perceived as development.

When applying the term of development to those outside of China, or "non-Chinese", the only way in which they can become developed, or accepted, is through Sinicization. The "outer" peoples, or "barbarians", are able to "become Chinese" by being culturally absorbed. In other words, they can "come and be transformed" through what was called laihua (Dikötter 2015). This process is indicative of the Yin and Yang model, and is therefore inherently Confucian (Dikötter 2015). As a person "becomes more Chinese" through education and development, they become less Yin and more Yang through a continual process. Development can only occur with a foundational suzhi. One's suzhi places them at a certain level within the Confucian hierarchical structure: The greater suzhi a person possesses, the higher they are regarded among their family and community. In terms of Confucianism, one's worth is always in context of their community. Because a person's primary mission as a citizen should be the betterment of their community, it is that person's community who determines a person's value, or suzhi. Confucianism's emphasis on societal hierarchy, in conjunction with Yin and Yang's dualistic structure, is apparent in ancient China's perception of race (Dikötter 2015).

Dikötter clearly makes a strong argument for the influence Confucianism has in formulating the Chinese perception of race, and this research attempts to legitimize his argument. The results below indicate the importance of education, development, and hierarchical structure and the unique aspect each plays in the way African blacks are perceived by Chinese immigrants. It is important to note Dikötter's argument that Chinese's supposed racist perception of blacks in Africa stems from the hierarchical beliefs of Confucianism. Tuttle argues that traditional Chinese thought, or Confucianism, is not inherently racist. Juxtaposing, Dikötter argues that inherent racism is present by translating the ancient phrase of minzu zhuyi literally as "racism" (Dikötter 2015).

\section{Materials and Methods}

\subsection{Methods Used}

Attempting to answer whether a certain individual or culture systematically views another as inferior requires physical interaction and communication. Personal interviews provided the opportunity to allow individuals to express their opinions and views without the limitations of rigid, pre-designed surveys. This project collected data through interviews in Maputo, Mozambique and Durban, South Africa-both cities with major Chinese migrant populations-and then organized the data on a ranking scale. Interviews were also conducted in Beijing with migrants who had moved back to China. All interviewees were recruited in person or through email and phone, and gave consent to be interviewed for this study. Interviewees from the hospitality sector were recruited during interactions at hotels which had a high rate of Chinese customers. Snowball sampling approach was used for construction sector interviews through an initial contact with the Chief Executive Officer of the Chinese Harbour Engineering Company, Ltd (Maputo, Mozambique). Further connections at the executive level arose from various other Chinese executives in southern Africa.

Each interview lasted between twenty minutes and two hours and varied in setting. Interviews took place over lunch, during a tour through construction sites, at company headquarters, in hotel lobbies, at shops in city malls, and at local offices throughout the city. Interviews were conducted in both English and Chinese, depending on the desire of the interviewee. A distinct effort was made to interview a diverse population of Chinese immigrants. While the construction sites and executive positions were male dominated, the hospitality sector made interviewing females much more feasible. An effort was also made to interview immigrants of different ages. Interviewees ranged in age from young twenties to upper sixties. All interviewee demographics can be seen in Appendix A.

Every attempt was made to cover a range of age and professional rank. Out of the 22 interviews conducted in Africa, eleven interviewees requested that their interview not be recorded electronically. Apart from four participants, every interview was conducted individually. As for those interviewed 
in pairs, their comments were still ranked individually. While many interviews were conducted in a public setting, participants appeared to not withhold comments due to any surrounding individuals potentially hearing their comments. That being said, one exception, a supervisor at a construction site, was interviewed in the same room as two local Mozambicans serving as Chinese translators. Due to the change in his demeanor and comments made after we continued to speak outside of the room, the presence of locals who could understand Chinese clearly altered how freely the participant felt with making comments about black Africans. This anomaly was accounted for in the data analysis.

The interview questions discussed with the migrants shed light on the trust they hold in black Africans; their personal experiences with fellow black co-workers, and supervisors; and everyday interactions with local blacks not involved in their work. For the interviews conducted in Africa, the main objectives discussed included: (1) Where the migrant migrated from in China and their primary reason they came to Africa, (2) the primary differences Chinese see between Chinese and Africans, and (3) how the interviewees define race. Each interview discussed the primary reasons each individual chose to move to Africa, when they did so, and their initial perception of local blacks. As for the interviews conducted in China, the same objectives were discussed, in addition to discussing how the interviewees felt their perceptions toward Africans changed following their return to China.

Furthermore, in order to better comprehend the source which creates racial perceptions, and the possible impact of historical and cultural beliefs, interviews addressed the impact of "traditional Chinese thought". In an effort to not lead interviewees toward discussing Confucianism, questions were asked regarding their belief of how much "traditional Chinese thought" impacted their perception of blacks." This was based off Link's research referring to "traditional Chinese values" as Confucianism, and vice versa (Link 2015). Because of its impact on Chinese tradition, and for the sake of this project, Confucianism will be considered the primary source of "traditional Chinese thought". Those participating in interviews were asked if they would like to speak about anything else they believe relates to the perception of blacks, the definition of race or ethnicity, or the relationship between Chinese migrants and locals.

For the sake of this project, three aspects of Confucianism are analyzed in detail: Hierarchical structures, the importance of education, and development. In his book On Confucius, Ni summarizes the fundamental thoughts of Confucianism, three of which are hierarchy, education, and citizen development (Ni 2002). Hierarchical structures are present within the family unit, and throughout society, garnering an appreciation and respect for ancestors and those with greater suzhi or quality. Suzhi, in short, can be thought of as one's value or quality in society. Education, Confucianism teaches, is both what a person should strive to achieve, but more importantly it serves as a validator of legitimacy within society. By passing difficult exams, one could be considered as a master based on ancient Chinese thought. Finally, through hierarchical structures, and education, one would be able to achieve the status of ideal citizen.

\subsection{Analytical Approach}

Upon completion of all interviews, data was coded to determine a relative scale of racial prejudices, or the lack thereof along several axes. The ranking system for the data includes ten sections: Comments favoring blacks/comments against blacks (1-6), influence of traditional "Confucian" values on the perception of blacks (1-6), Africa's perceived benefit from Chinese migration and investment, the birth city of interviewees, time spent in Africa, occupation, age range, highest education achieved, and other countries where one lived in Africa.

The sections which rank participants on a scale of one to six were created from an objective scale in terms of prejudiced and/or non-prejudiced statements about black Africans. For example, in the category of "Comments prejudiced toward blacks", interviews which included phrases such as “坏人” (bad person), “懒” (lazy), “小偷” (thief), and “罪犯” (criminal) received rankings of 4-6. Such rankings were all made in relation to one interview which was distinctly racially prejudiced in nature. In the same category, if the participant failed to make any seemingly prejudiced statements, they received a 
rank of 1 and a rank of 3 if their statements talked about "cultural perceptions" against blacks, but did not claim such prejudiced beliefs as their own.

In order to ensure that a lack of prejudiced statements toward blacks, or the presence thereof did not factor in as a "pro-black" perspective, or vice versa, each interview was also ranked in terms of “Comments Favoring Blacks". Statements such as “可靠” (dependable), “努力” (hard working), or “聪明” (smart) received a rank of 4-6. Indifferent comments received a rank of 1, and comments relating to the cultural ability of blacks, but not necessarily the personal opinion of the interviewee, received a rank of 3. A third section relates to the impact of Confucianism on Chinese migrant's worldviews. Confucianism has played an integral role in the development of China, and despite a diminished practice of Confucianism, its ideals and views regarding morality still heavily influence modern day Chinese thought (Ni 2002).

Furthermore, since Sinicization and the accompanying hierarchical structure is inherently Confucian, it is fair to hypothesize that Chinese immigrant's supposed racist perception of blacks in Africa stems from Confucian values (Dikötter 2015). In hopes of not leading participants, interview questions refrained from using the term "Confucianism" or "Confucius" and instead used the term "Traditional Chinese thought" when asking participants about how they believe Chinese culture has influenced their views. Participants who directly related their beliefs to that of Confucianism received a ranking of 6 , while those who stated they value the impact traditional thought has on their views received a rank of 3 , and those who do not attribute their beliefs to traditional thought received a ranking of 1.

Finally, each participant's remarks regarding the benefit China brings to Africa was ranked from 1 to 6. Questions regarding the benefit reaped from China's investment and migration to Africa seeked to determine if many Chinese migrants believe "helping" Africa and its residents is a moral obligation under the umbrella of moral Confucian citizenship, or is the benefit only a secondary effect from what China gains by investing in Africa? Participant's remarks which stated that China is invested in Africa for altruistic reasons and is helping the continent grow for its own good received a ranking of 6. Juxtaposing this, comments which insinuated that Chinese persons only migrated to Africa to become financially invested for selfish reasons received a ranking of 1 . For the purposes of this paper, we have provided a qualitative summary of the interview data with some key quotations to exemplify the points made by the respondents.

\section{Results and Discussion}

\subsection{Perceptions of Chinese Citizens Residing in Africa}

An interesting initial insight from the interview data revealed that some respondents did not necessarily believe China's involvement helped African nations; indeed, the respondents seemed to believe African culture helped their own lifestyles. Participant number two stated, "Chinese culture has a lot of pressure and stress. Here [Africa] is less complicated. If you like it quiet, you can enjoy it here" (Interview 2). Furthermore, in a separate interview, another participant stated, "In Africa today there is equality, and social harmony and contentedness" (Interview 1). Comments such as this produce a positive outlook on African culture and way of life instead of an outlook which viewed Africa as a place in need of desperate assistance. Participant number one even stated, "Our cultures are not the same. They [Africans] are comparatively more optimistic compared to people in my country. Chinese people are a little more conservative. Africans are happy every day. They dance and sing! In China, we don't do this" (Interview 1).

These comments serve as an anomaly to the hierarchical superiority of China in comparison to Africa. Only interviewees who worked as small business owners made similar comments. This very well could be a result of their more flexible schedules and ability to engage with local Africans in a non-work, more relaxed environment. 
Despite the positive outlook on African culture, Chinese small business owners made the least amount of positive comments about Africans in comparison to construction and hospitality employees. Some comments exemplified blunt, negative opinions about blacks, while others remained more subtle. "I don't trust them because they are black", remarked Participant number three. He continued with his remarks stating, "Africans just came out of the jungle age" (Interview 3). Other business owners spoke in a more educated manner about African history. "I have personally read some of their history; they have worked through a lot of struggle to achieve the power they have today" (Interview 1). They understood the history of farming in China and seemed to apply a higher suzhi to farmers. In fact, two thirds of business owners argued that farmers and poor people are the most trustworthy people in society.

It is important to reiterate that while small business owners made the least amount of positive comments, they did not, by default, make the most prejudiced comments regarding blacks. The fact that business owners made the least amount of positive comments coincides with their individualistic attitude of why they came to Africa in the first place. The small business owners each stated that they came to Africa to pursue their own interests and never intended on returning to China. Small business owners seemed to lack any loyalty to China, and did not feel the need to remain connected with China in many ways. For example, most shop owners migrated with their whole families, and left China without the intention of returning. In comparison, hospitality and construction employees moved to China as employees of larger Chinese businesses. They intend on returning to China after two to three years, and thus view themselves as part of the Chinese effort to improve Africa. Small business entrepreneurs moved to Africa for their own individual benefit and did not view themselves as part of China's larger movement to improve relationships with Africa.

When asked directly about how blacks are perceived in China, a participant responded, "China doesn't have racism. They have a balanced society (平衡的文化)" (Interview 2). He continued to compare the opinions of Chinese natives still living in China, with that of Chinese in Africa. "China does not have racial discrimination," He stated, “... but Chinese people in Africa have a little racism and this is a problem" (Interview 2). Contrasting, while he argued that racism does not exist in China, he followed his statements with, "Because of China's special culture, color is sensitive. Chinese people want to be white because it represents superiority and high class. They all want white skin" (Interview 2). The interesting aspect is that to many Chinese, lightening one's skin is not a wish, but a historical way of life. The Chinese culture has been altering this phenotypic trait for millennia. The "yearning for lightness" and purchasing of skin-lighteners is expansive across the global south (Glenn 2008). The effort to lighten one's skin in China, and the blunt assignment of value or suzhi based on lightness dates to classical China (Glenn 2008). For example, Yan Fu is quoted as stating, "Yellow and white are wise, red and black are stupid, yellow and white are rulers, red and black are slaves, yellow and white are united, red and black are scattered" (Dikötter 2015). The desire for Chinese to lighten their skin, or view it as a normal practice, is not merely a fad but a deeply historical practice.

This line of thought based on skin tone does not hold across all business owners interviewed, as can be seen in the following comment: "I often encounter black and white customers. The cultures are not different between blacks and foreigners" (Interview 1). While the latter comment contradicts the previous one regarding the "superiority" of whites, it does not address the comment about the apparent lack of racism in China. This opens discussion for whether racism is present in Chinese culture, or whether many Chinese natives are oblivious to its existence. The unifying comments regarding the trustworthiness, or higher suzhi for farmers and the elderly as opposed to businessmen, or elites, insinuates that Chinese culture is much more focused on social class, suzhi, and education than racial color. All small business owners who were interviewed stated that farmers, and the elderly, on average, are the most trustworthy people. However, they also stressed, vividly, the importance of education. Each participant, in one way or another, stressed the need for education, specifically in Africa. The majority claimed that blacks were not trustworthy not because of their race, but because of their lack of education. The idea of education at hand is not merely a classroom acquisition of knowledge, but rather a journey toward inner cultivation with the hope of an improved suzhi as an end state. 
While only half of the small business owners brought up Confucianism when discussing the role of traditional Chinese culture, their comments regarding the importance of education, and respect of the elderly indicate the influence of the Confucian hierarchical structure and value of learning. Confucius strongly emphasized the importance of hierarchy, especially in terms of age. In addition, one of the fundamental pillars of Confucian teachings is education and its role in creating good citizens. It can be concluded that small business owners emphasized hierarchy, and educational development over the presence of racial prejudice when asked about locals. While they differed on how much they trusted blacks, they remained united on the black's ability to become educated if given the opportunity.

Out of the three different groups of workers interviewed, hospitality workers made the most prejudiced comments about blacks, made the most comments favoring blacks, and was the group which gave Confucianism the most credit for influencing their opinions today. Chinese employees at the hotel represented an eclectic range of opinions. For example, Interviewee 24 could not believe that anyone could ever think local blacks did not like Chinese people, and vice versa. "They love us and we like them," he stated (Interview 24). However, the Hotel Manager bluntly stated, "Black people are very horrible people. They are cruel and callous" (Interview 16). The manager went further claiming, "I feel like they seduce people. They only like money and they steal. They want money but don't want to work for it" (Interview 16).

Other workers expressed similar feelings in terms of prejudiced statements about blacks. "Locals are dangerous", claimed another hotel employee, "They are thieves and dislike the Chinese. In Zimbabwe and Mozambique, blacks kidnap Chinese and all types of foreigners. It is a serious problem" (Interview 21). The inherent contradiction within these statements is apparent; however, they did not seem to be spoken in error by the interviewee. She consistently repeated her belief that "they love us and we like them... but they [blacks] are thieves and dangerous" (Interviewee 16). Many of these comments seem extreme; however, they are representative of how many employees perceive locals.

Regardless of the severity of prejudiced comments made, many of the same participants made neutral and positive comments about blacks. The gym manager of the hotel sat quite opposite of Interviewee 16 in terms of how she perceived local Africans. "They are nice people. I see no difference between me and them. The only negative comment I have is that at times, black males seem dominant" (Interview 17). The hotel manager even stated, "I know many blacks do not have work, and Chinese companies can at least employ them" (Interview 16). While she admitted she views blacks as thieves, she said many steal because they need money and because it is their culture (Interview 16). She explained that such behavior cannot be solely blamed on the individual when their surrounding culture accepts such behavior. Interview 14 focused on the value of individual relationships with locals. He states, "I don't just look at people's faces [their race/color]. If people are friendly, I am friendly. However, if I get burned, I won't forget it" (Interview 14).

Many viewed the blacks not as inferior, but simply as a group of people who could use help. This perception falls in-line with the Confucian hierarchical construct: The Chinese migrants do not want to control the locals, but feel an innate desire to help them. For example, "They need jobs and money. We [China] can help them and supply both. We create jobs for them because they have none" (Interview 24). The more neutral comments portray a balanced, yet contradicting attitude about blacks. On one hand, interviewees spoke openly regarding their negative views about blacks. However, they also shed light on positive aspects about local black culture and behavior.

In addition to answering questions about the influence on Confucianism, many hospitality workers expounded on how Chinese natives in China view blacks, and the role China's culture plays in creating racial perceptions. On the negative side, participants expounded on a difference between blacks in Africa and blacks in China. "Blacks in China do not go beyond their bounds. They know their place", was one way the difference was explained (Interview 16). She continued to claim that Chinese natives who had not left China had not seen "African blacks", and therefore would not know how "African blacks" act in comparison to "Chinese blacks". "This is why many Chinese in China have a high opinion of blacks", she remarked (Interview 16). Interview 17 brought another perspective 
into discussion by saying, “... It is not blacks who I do not trust. I do not trust middle-class Chinese businessmen" (Interview 17). She stated that in China, many middle-class Chinese businessmen have created a reputation of being unfair and untrustworthy.

Like many small business owners, many of the hotel workers referred to the need for education and the significant benefits it provides to a community. Almost every employee at some point in their interview, expressed their hope that black Africans will have access to better education for the sake of improved culture and moral behavior. They also referred to Confucianism's hierarchical structure, but in a different manner to small business owners. They viewed Africa as a whole, not simply black people, as lower in the hierarchy of cultures. Interviews 14, 17 and 21 focused heavily on how much China can and should help Africa because of its underdeveloped and slowly developing culture. Of course, these opinions could have arisen from a perception of cultural superiority, a true desire to help, a Confucian hierarchical influence, or a combination of each. Nevertheless, the opinion of blacks, while focused on race to some point, was also driven by the need for education and development.

The largest percentage of participants interviewed for this project worked in the construction field. They ranged from laborers at construction sites, to supervisors, project managers, CFOs, and even CEOs in various Chinese construction companies. Construction employee's comments ranged from prejudiced to favorable; however, it was evident that their beliefs hinged on two specific beliefs: Importance of education and the benefit Chinese investment brought to Africa. On average, construction workers scored nearly one whole point higher than hospitality workers and small business owners when asked about how much Chinese presence in Africa benefitted locals and the local economy.

Interviewee 19, an accountant from a Chinese construction company in Maputo, is a prime representative of the various comments from construction employees. He began by stating that Chinese companies, by law, must employ locals, specifically black locals (Interview 19). He followed that statement by saying, "Black, yellow, and white people are all the same for our company" (Interview 19). Nevertheless, statements such as, "Chinese people don't like black people because they do outlaw things" stole credit from his previously mentioned statements (Interview 19). While this seems like a blanket statement, the interviewee specifically noted that determining a person's dependability or trustworthiness must be decided individual by individual, not by categorizing a whole race or culture (Interview 19).

In terms of how much Chinese thought and culture affected the perception toward local blacks, the accountant spoke quite abundantly. For the most part, he claimed that Chinese people are not racist, but rather just shy (Interview 19). Shyness can often be confused for rudeness, but as Interview 14 also stated, if people are friendly, most Chinese will also be friendly (Interview 14). Throughout his interview, he continuously gave reference to Confucian principles, until finally stating, "If you truly want to know the Chinese opinion, and how they think, you must learn about Kongzi (Confucius)" (Interview 19). As an educated individual, he spoke of Confucian principles in detail. While his comments regarding the importance of Confucianism were not rare, the detail in which he spoke about Confucianism stood out as an anomaly amongst the other interviews.

The Project Manager of a nearby construction company spoke with similar regard about Confucianism, and with an increased emphasis on why blacks suffer because of a lack of education. Whereas Participant 16 stated that blacks steal because it is their culture, the Project Manager believed that thievery resulted not from culture, but a lack of moral education (Interview 18). He claimed the lack of education was to blame for pilfering and a lack of trust between some Chinese and local blacks (Interview 18). The participant naturally drew a comparison between blacks in China and those he worked with and encountered in Africa. Instead of assuming local blacks were all untrustworthy, he observed how many blacks in China received high levels of education, and thus functioned in society with an increased moral compass (Interview 18). Their education, in conjunction with a strong economic foundation, allowed blacks in China to be viewed differently than those in Africa. Based on his understanding, "Some Africans have an education, but their families often do not have money to help them move out of the cycle of generational poverty" (Interview 18). Regardless of the balanced 
comments he made, the Project Manager also conceded that on average, most Chinese do not view blacks, whites, and Chinese the same (Interview 18). He did not specify if the difference insinuated inequality, or just a lack of similarity.

The remaining construction workers continuously emphasized similar beliefs. At the Catembe Bridge construction site, several men concurred with aforementioned statements about how it is not racism, but a lack of education and development which causes many Chinese to view blacks in a negative light. "I came here [to Africa] two years ago", stated one worker, "I work every day and only get five days off every year. I came because of the increase in pay. We pay the local blacks a fair wage to work, but they do not understand hard work. They expect to get weekends off, or to go home at five, but that is not how we work. It is not the Chinese work ethic (Interview 7). From a western perspective, where an average person works eight hours a day, and does not work on the weekends, his statement might seem harsh. But his friend explained further, "The local blacks here do not have a work ethic because they have not been taught how to have one. They will only learn through education. Look around, we taught them all the skills they need to work here. It is not that they cannot learn, they simply have not been taught" (Interview 8). As for who the responsibility of educating the local population falls on, "I am not sure. Hopefully the Chinese presence influences the local population and government to understand the value of education and hard work" (Interview 7). Every employee who was interviewed at the Catembe Bridge construction resonated with the importance of education, and the value it can bring to a culture and future development.

While most construction employees spoke bluntly about their opinions, and with no apparent filtering of thoughts, the CEO of one construction company clearly spoke like a polished politician, noticeably aware of things not to say. In other words, his business experience, knowledge of the English language, education, and time spent working with governments, allowed him to answer questions in a comparatively polished manner which represented the Chinese government and his company in the most positive light. Similar to his fellow construction-oriented workers, he spoke about the value of helping Mozambique develop through infrastructure, and the value of education. He also expounded on that importance of westerners understanding how Chinese people perceive Africa, development, and racism. It was of great importance to him that westerners know that many Chinese businesses and people want to work with the west, not against them; and, "... China does not view Africa as grounds to exploit, but rather develop through cooperation" (Interview 20). Observations of Chinese mineral exploitation in Africa are grounds to disregard the latter part of his comments; nevertheless, although he answered questions with what one might call a "textbook answer", he also spoke with a genuinely caring attitude.

Overall, as the part of the Chinese community which engages with local blacks the most, construction employee's comments focused heavily on education and development within the local community. From a western lens, it may seem as though they portrayed an attitude of racism and prejudice; however, their remarks displayed a belief that local blacks were disadvantage because of their lack of education, not simply the color of their skin. Their comments were harsh and discriminatory in nature, but most of the participants did not make prejudiced statements with the same dislike for local blacks as many previously mentioned hospitality workers. They provided caveats for the statements such as, "with an understanding of development and a base education, the locals will progress." Statements of this nature resonate with the Confucian principles of suzhi, and the need for suzhi to attain development which I discussed at the beginning of this article.

\subsection{Perception on Returning to China}

In order to gain a more nuanced understanding of the Chinese perceptions toward local black Africans, the aforementioned data was discussed with Chinese workers, journalists, and executives who had migrated to various African states for an extended period of time and then returned to Beijing. These interviewees compared their own experiences with the perceptions of those mentioned above and surprisingly, expressed a more open and accepting demeanor toward black Africans. Not only 
did each individual who had returned to China feel a sense of admiration and gratitude toward black Africans, but they also recognized the prejudices many Chinese who have never visited Africa or those who still live in Africa hold toward blacks.

The interviewees in Beijing included an educator who spent a year teaching in Ghana, a Chinese CCTV correspondent who spent multiple years living in over ten African states, and an executive from a security scanning company who has worked in various African states for over ten years. The interviewees ranged in age from mid-20s to mid-50s and the names used in this paper are pseudonyms for the sake of anonymity. Throughout the interviews, two primary themes emerged as the participants considered the opinions mentioned above and shared their own experiences.

First, while the group of participants living in Beijing possessed a welcoming attitude toward black Africans, they were open about the prejudices many Chinese workers in Africa hold against local blacks in Africa. For example, Wang, who spent a year working in Ghana at the Meltwater Entrepreneurship School of Technology in Akkra stated that while personally, he experienced hope and trust among black Africans, "To be frank, most people in China don't like Africans that much. Because of language barriers, people don't feel safe. Without any communication, people [Chinese] feel threatened". However, he believes miscommunication is accentuated through media, "In the movies we see blacks are always poor and fighting in wars in Africa, so that's what many Chinese people think all of Africa includes".

Feng Guo, a CCTV Correspondent who spent a several years in ten African countries, explained similar sentiments about local black Africans. He explained that three groups of Chinese people concerning Africa: workers, tourists, and those who have never been or do not intend to go. "As a correspondent I witnessed many warm hearted and nice local black Africans", Feng Guo said, "However, for most Chinese workers who move to Africa, they have only ever known Chinese people, so when they get to Africa the stark difference in physical appearance incites fear. While these statements do not justify the racial prejudices, they do help explain why they exist. Wang, who spent many years living in the west prior to traveling to Africa even said, "I remember flying to Africa being scared to death. I thought it was going to just be a war zone." The three participants interviewed in Beijing accredited mere exposure to the people of Africa as the primary reason they now possess hope and trust in local black Africans.

Granted, interviewee Wang mostly worked with highly educated and driven high school students from western Africa; and with CCTV, Feng Guo was constantly on the move reporting from different countries. But both believed it was important to distinguish their perception of black Africans from the status-quo. In terms of other Chinese groups, "Chinese people who have never been [to Africa] tend to be wrong. .. they think Africans are dirty, poor, dangerous. It's just wrong," Feng Guo claimed. "Tourists have a chance to really see friendly Africans", he said with a grin.

Throughout their time in Africa, unique experiences brought each participant to view local blacks in a positive light. For example, Kevin, a regional manager for a large-scale security scanning company recalled an instance when he witnessed a black African stop a foreigner from killing a bird in the street. "It seems like a small incident, but that made me realize that he [the local black African] was a caring human". These experiences brought on an individual humanness which broke down prejudices. During his year in Akkra, Wang engaged and taught with some of the brightest young minds across Africa. The Meltwater Entrepreneurship School of Technology recruits a small, selective class of students who are driven, focused, and persevering, which left an unforgettable impression on Wang in terms of the potential black Africans have. Overall, the personal experiences during their time in Africa left Wang, Feng, and Kevin with a positive and hopeful impression of black Africans.

Second, the participants discussed how the massive expansion of technology and increased global trade will hopefully relieve interracial tensions between Chinese and black Africans. Feng Guo held this conviction the strongest. He believes heavily in the visual role tech will play in bringing humans together in a mutual level of understanding. "When we look at an I-phone, we need to see more than a phone. We see the microprocessor invented in the west and produced in the east. We see the assembly 
in China and the shipment across the globe. With simply our phones, we see how much we need each other." This complemented Wang's comments about the exponential growth in Africa of the use of cell phones and other devices that offer access to unlimited information. Because of technology, black Africans share their stories globally now and outsiders see the growth in Africa, Wang claimed. "I know this will bring understanding in the way movies have brought misconception".

Kevin concurred in terms of the power infrastructure and technology possess to build stronger relations between Chinese and African people. "Many Chinese companies are going above and beyond to partake in social development and improve social issues in Africa. They really do care and are not just there for money." Unlike western states who have been involved in Africa, Feng Guo notes that China has the 后发优势 which translates as the "late-comer advantage." He believes this allows China to utilize its involvement in Africa and its technology to create trusting and beneficial relations instead of exploitive partnerships.

It should be noted that while their overall comments were favorable toward black Africans, and the participants generally disagreed with the sentiments of Chinese migrants in Africa, Kevin did maintain some prejudices which he clearly expressed. "We know that blacks listen to whites, especially in South Africa. We take advantage of the black-white relationship in South Africa. A black man is fearful of a white, and will take instruction from him, but not from a Chinese man", noted Kevin. He also mentioned that the blacks have no reason to fear Chinese involvement. "They are narrow minded and need to see the bigger picture that Chinese companies are not there just to take things from them."

Additionally, unlike the considerable mentions made by the Chinese interviewed in Africa regarding how much Confucian thought is influencing racial perceptions in Africa today, the interviewees in Beijing left Confucian thought practically unmentioned. In fact, Feng Guo stated that it is a great thing that Confucian thought and its hierarchical structure is not as influential as it has been in the past. "China has a rich history, yes, but we also got a lot wrong, much of which is associated with Confucian thought. There is a lot we [China] can learn from the west and their culture", he said. "It is great to have a long history, but the benefits of having a shorter history like in the US is the ability to be flexible and create without the constricting ties of ancient culture. China needs that flexibility in order to understand the world and continue to grow."

It is clear that exposure to the unknown breeds trust and understanding. Just as the construction supervisors mentioned above were the most accepting of local black Africans, the participants who have spent time in Africa and then returned to Beijing projected a perception of understanding and acceptance. They had seen the "different" and returned home with a broader sense of perspective. Regardless of the role history, or specifically Confucian thought, has played in the perception of Chinese migrants toward blacks, what is of greater importance is understanding that extended exposure to different races is the primary way to deconstruct prejudices and construct trust.

\section{Conclusions}

Our research suggests that Chinese migration to Africa has an important reflexive dynamic with regard to change in perceptions about race and development. Confucian ideology also appears to be more malleable in the context of these perceptions, but the transference of such perceptual change in Chinese politics deserves further study. China's investment in Africa is likely to be a long-term engagement, and the kind of positive changes in perception that are noted augur well for more cooperative relations and mitigation of conflict. We are conscious of cultural relativism in the analysis of such geographically dispersed societies, but common elements of transference of some cultural attributes clearly reinforce commonality as well, such as respect for the elderly. Nevertheless, our research also showed that some stereotypical prejudices in Chinese merchant communities remain entrenched despite an appreciation for African worldviews and coping strategies with adversity. There is still very little inter-marriage between Africans and Chinese, and even longtime friendships across racial lines seem elusive. Further prospective sociological research is needed to ascertain how 
such lasting relationships might emerge and sustained. The reflexive approach to research which we have followed could be further developed and tracked over time to monitor the changes in ethos in both Africa and China. At the same time, there should be greater attention also paid to differences in outcomes in relations between Chinese and African cultures in a range of countries. As noted from our historical review, the relationship between the two cultures is more strained in Western Africa where there is a lesser history of maritime trade and exposure of Africans to Chinese migrants. Refinement of scales of analysis should thus be a priority as well in future research. Our aim in this paper has been to offer some initial insights on the perceptual changes in this arena through in-depth and structured qualitative methods that can pave the way for more detailed quantitative analyses in the future.

Author Contributions: The conceptualization and methodology for this article was M.P.'s. The idea to interview resident's currently living in China was the idea of S.A. and all interviews were conducted by M.P. The paper was jointly written for this publication.

Funding: This research was funded by the University of Delaware Department of Geography.

Acknowledgments: Thank you to Peter and Vanessa Coelho for making the research in South Africa and Mozambique possible. Also, thank you to Delphis Levia and Afton Clarke-Sather for supporting the research and making it possible. The primary author was a Schwartzman Scholar at Tsinghua University in Beijing, China (September 2017-July 2018) during part of the period when this manuscript was prepared for submission.

Conflicts of Interest: The authors declare no conflict of interest.

\section{Appendix A.}

Interviewee Demographics-This table describes each interview by Age, Occupation and Birth City.

\begin{tabular}{|c|c|c|c|}
\hline CODE & Age Range & Occupation & Birth City \\
\hline Interview 1 & $25-30$ & Bead shop owner & Beijing \\
\hline Interview 2 & $35-40$ & Traditional Medicine Shop owner & Beijing \\
\hline Interview 3 & 40 & Restaurant Owner & Taipei \\
\hline Interview 4 & 23 & Translator & Maputo \\
\hline Interview 5 & 23 & Translator & Maputo \\
\hline Interview 6 & 22 & Translator & Maputo \\
\hline Interview 7 & 26 & Construction Head Supervisor & Shanghai \\
\hline Interview 8 & $30-35$ & Construction Supervisor & Unknown \\
\hline Interview 9 & 30 & Construction Supervisor & Unknown \\
\hline Interview 10 & $30-35$ & Construction Supervisor & Xian \\
\hline Interview 11 & $30-35$ & Construction Supervisor & Xian \\
\hline Interview 12 & 25 & Construction Supervisor & Unknown \\
\hline Interview 13 & 40 & Head of US Cultural Center, Maputo & Maputo \\
\hline Interview 14 & $40-45$ & Generator Company Director & Maputo \\
\hline Interview 15 & 50 & House Service School Owner & Maputo \\
\hline Interview 16 & 30 & Generator Contraction and Translator & Hefei \\
\hline Interview 17 & 25 & Masseuse & Hefei \\
\hline Interview 18 & $25-30$ & Hotel Manager & Shanghai \\
\hline Interview 19 & 24 & Hotel Gym Manager & Shanghai \\
\hline Interview 20 & 35 & Construction Manager & Shanghai \\
\hline Interview 21 & 30 & Accountant & Shanghai \\
\hline Interview 22 & 35 & Harbour Construction Company VP & Hangzhou \\
\hline Interview 23 & $30-35$ & Construction Company Operations Director & Xian \\
\hline Interview 24 & 35 & Clothes Manufacturer & Maputo \\
\hline Interview 25 & $55-60$ & Commercial Boat owner and retired & Maputo \\
\hline Interview 26 & $65-70$ & Hotel Janitor & Bulawayo \\
\hline Interview 27 & 65 & Shop Owner & Maputo \\
\hline Interview 28 & 30 & Construction Representative & Xian \\
\hline Interview 29 & 26 & Construction Representative & Xian \\
\hline
\end{tabular}




\section{Appendix B. Interview Guide}

\section{General Information:}

- Where in China are you from?

- What is your current occupation?

- When did you come to Africa?

- Why did you choose to come to Africa?

- Have you talked to anyone else about your immigration experience?

- $\quad$ Do you get along with the locals?

- In what ways are the locals the same or different from you?

\section{Interview Goals:}

- $\quad$ Discuss where the migrant is from in China and their primary reason to coming to Africa

- $\quad$ Discuss differences between Chinese and Africans, from the Chinese perspective

- Discuss personal opinion of race

- $\quad$ Discuss ideas of how Confucianism impacts their life

- $\quad$ Allow participant to offer other information about their views on relations between Chinese and Africans and perceptions of Africans

\section{References}

Archer, Margaret. 2007. Making Our Way through the World: Human Reflexivity and Social Mobility. Cambridge: Cambridge University Press.

Brazinsky, Gregg. 2017. Winning the Third World: Sino-American Rivalry during the Cold War. Chapel Hill: University of North Carolina Press.

Cardenal, Juan Pablo, and Heriberto Araújo. 2013. China's Silent Army: The Pioneers, Traders, Fixers and Workers Who Are Remaking the World in Beijing's Image. New York: Crown.

Chen, Zhiyong. 2012. Climate's Moral Economy: Geography, Race, and the Han in Early Republican China. In Critical Han Studies: The History, Representation, and Identity of China's Majority. Berkeley: University of California Press, pp. 73-91.

Chen, Guo-Ming, and Jensen Chung. 1994. The Impact of Confucianism on Organizational Communication. Communication Quarterly 42: 93-105. [CrossRef]

Chichava, Sérgio, Jimena Duran, Lídia Cabral, Alex Shankland, Lila Buckley, Tang Lixia, and Zhang Yue. 2013. Brazil and China in Mozambican agriculture: Emerging insights from the field. IDS Bulletin 44: 101-15. [CrossRef]

Chin, Tamara. 2012. Antiquarian as Ethnographer: Han Ethnicity in Early China Studies. In Critical Han Studies: The History, Representation, and Identity of China's Majority. Berkeley: University of California Press, pp. 128-46.

Coltart, David. 2016. The Struggle Continues: 50 Years of Tyranny in Zimbabwe. Auckland Park: Jacana.

Crossley, Pamela Kyle. 1990. Thinking about ethnicity in early modern China. Late Imperial China 11: 1-35. [CrossRef]

Dikötter, Frank. 2015. The Discourse of Race in Modern China. Oxford: Oxford University Press. First published in 1992.

Elliott, Mark C. 2001. The Manchu Way: The Eight Banners and Ethnic Identity in Late Imperial China. Palo Alto: Stanford University Press.

The Economist. 2014. Empire of the Sums. Available online: https:/ /www.economist.com/books-and-arts/2014/ 08/23/empire-of-the-sums. (accessed on 11 May 2017).

Glenn, Evelyn Nakano. 2008. Yearning for Lightness: Transnational Circuits in the Marketing and Consumption of Skin Lighteners. Gender \& Society 22: 281-302.

Ilhéu, Fernanda. 2010. The Role of China in the Portuguese Speaking African Countries: The Case of Mozambique (Part II). Abuja: Centre of African and Development Studies, Universidade Técnica de Lisboa. 
Jinyuan, Gao. 1984. China and Africa: The Development of Relations over Many Centuries. African Affairs 83: 241-50. [CrossRef]

Kuang, Emmanuel Ma Mung. 2008a. Chinese Migration and China's Foreign Policy in Africa. Journal of Chinese Overseas 4: 91-109.

Kuang, Emmanuel Ma Mung. 2008b. The New Chinese Migration Flows to Africa. Social Science Information 47: 643-59. [CrossRef]

Li, Anshan. 2005. African studies in China in the Twentieth Century: A Historiographical Survey. African Studies Review 48: 59-87.

Liggett, Walter W. 2007. The Rise of Herbert Hoover. Vancouver: READ Books. First published in 1932.

Lin, Edwin. 2014. "Big Fish in a Small Pond": Chinese Migrant Shopkeepers in South Africa. International Migration Review 48: 181-215. [CrossRef]

Link, Perry. 2015. What it Means to be Chinese. Foreign Affairs 94: 25-31.

Mullaney, Thomas S., JamesGros Leibold, Stéphane Gros, and Eric Vanden Bussche. 2012. Critical Han Studies: The History, Representation, and Identity of China's Majority. Berkeley: University of California Press.

Ni, Peimin. 2002. On Confucius. Medina County: Wadsworth.

Park, Yoon Jung. 2009. Chinese Migration in Africa. Johannesburg: South African Institute of International Affairs.

Roque, Paula. 2009. China in Mozambique: A Cautious Approach: Country Case Study. Johannesburg: South African Institute of International Affairs.

Statistics South Africa. 2011. Mid-Year Population Estimates; Statistical Release. Pretoria: Statistics South Africa.

Tapp, Nicholas. 2012. The Han Joker in the Pack: Some Issues of Culture and Identity from the Minzu Literature. In Critical Han Studies: The History, Representation, and Identity of China's Majority. Berkeley: University of California Press, pp. 147-70.

Teng, Emma Jinhua. 2012. On Not Looking Chinese: Does Mixed Race Decenter the Han from Chineseness? In Critical Han Studies: The History, Representation, and Identity of China's Majority. Berkeley: University of California Press, pp. 45-72.

Tschakert, Petra. 2016. Shifting Discourses of Vilification and the Taming of Unruly Mining Landscapes in Ghana. World Development 86: 123-32. [CrossRef]

Tuttle, Gray. 2015. China's Race Problem. Foreign Affairs 94: 39-47.

Yap, Melanie. 1996. Colour, Confusion and Concessions: The History of the Chinese in South Africa. Hong Kong: Hong Kong University Press. 